\title{
Surface Hardened Gold Alloys
}

\author{
PREPARATION BY THE USE OF A BORONIZING TECHNIQUE
}

\author{
Fukuhisa Matsuda and Kazuhiro Nakata \\ Welding Research Institute, Osaka University, Japan
}

\author{
Masaki Morikawa \\ Central Research Laboratory, Mitsubishi Metal Corporation, Japan
}

\begin{abstract}
A process for the surface bardening of bigh gold-content alloys would improve their performance in a variety of applications. The effects on their bardnesses of beating pure gold and alloys of gold, containing titanium, chromium, nickel or iron, with boron powder in an argon atmosphere at 900 to $950^{\circ} \mathrm{C}$ for six hours bave therefore been studied. The findings are reported in this article.
\end{abstract}

Gold is used not only as a store of wealth, but also for decorative, dental and a host of industrial purposes. It finds applications, for example, in jewellery, personal ornaments, watches, spectacles, writing accessories, dental restorations and prostheses, semiconductor technology, bonding wire for integrated circuits, electrical contacts of many kinds, and in solders and special brazing alloys. For some of these applications, such as the production of gold foil and of fine bonding wires, the softness and high ductility of the metal are an advantage. For other applications, however, and in particular those in which it is exposed to abrasive wear, these attributes may be disadvantageous.

Despite these facts, the hardening of the surface, as opposed to the bulk hardening, of gold and its alloys has not, so far as the authors are aware, been studied systematically. Surface hardening of other metals and alloys by the diffusion of boron into their surfaces from powder at elevated temperatures is known. The thicknesses of the hardened layers is usually greater than those of surface coatings as achieved by chemical or physical vapour deposition.

\section{Basic Principles}

Preliminary studies demonstrated that it was impossible to form a hardened layer on pure gold by heating it with boron powder. This was not unexpected from the low reactivity of the metal and consideration was immediately given to the possibility that surface hardening might be induced if there was present in the gold an alloying element with a strong affinity for boron. The mechanism by which this might take place was visualized (see Figure 1) as occurring through boride formation in the surface layers of the gold as a result of interaction between atoms of the alloying element and atoms of diffused boron.

The free energies of boride formation by titanium, chromium, nickel and iron, as derived from the literature $(1,2,3)$, are listed in Table I. These data indicated that all four of these elements might be expected to form borides with diffused boron in metallic gold. Moreover, all four of these metals (see Table II) have significant solid solubilities in gold.

Consequently the susceptibilities of gold-rich gold-titanium, gold-chromium, gold-nickel and gold-iron alloys to surface hardening on heating with boron powder have been studied.

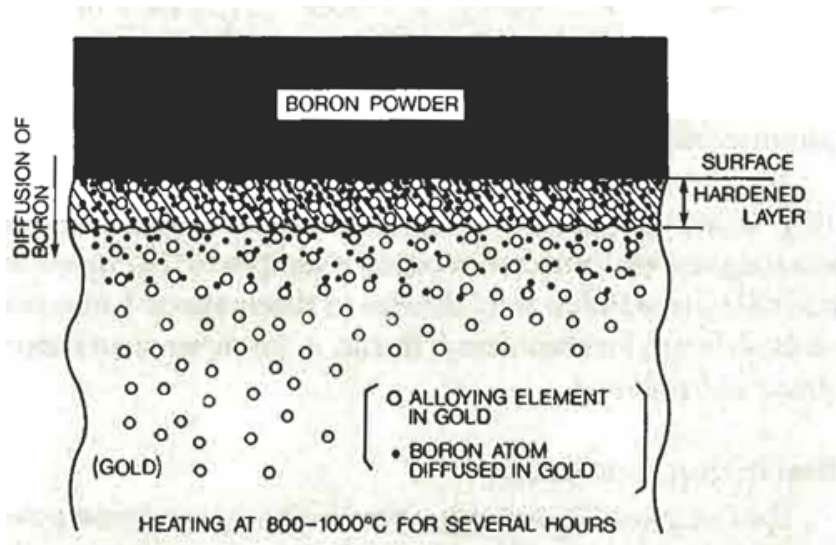

Fig. 1 Schematic illustration showing the mechanism of surface hardening of a gold alloy by the boronizing technique

Table I

Free Energy of Boride Formation of Ti-B, Cr-B, $\mathrm{Ni}-\mathrm{B}$ and $\mathrm{Fe}-\mathrm{B}$ Systems

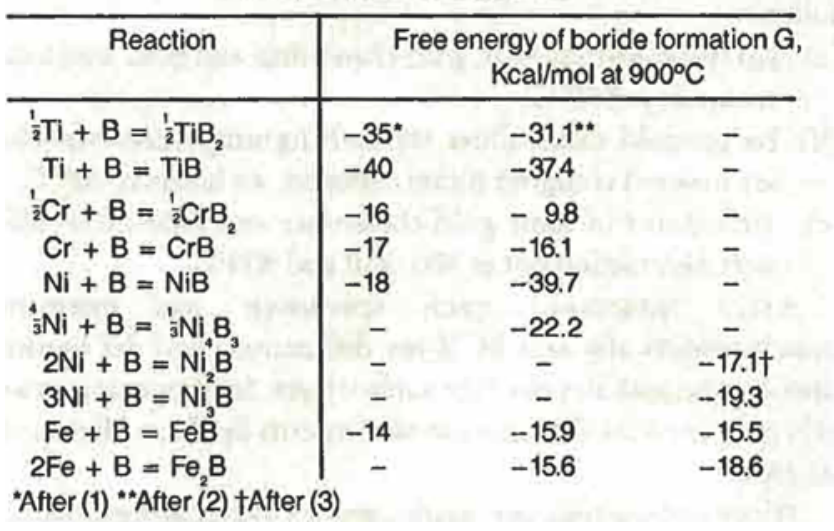

\section{Alloys Investigated and Preparation}

The compositions of the alloys studied are given in Table III. Their titanium, chromium, nickel or iron contents were 2 to 5,1 to 10,5 to 35 and 1 to 30 per cent respectively. In addition to these binary alloys, an 18-carat gold-nickel-palladium alloy, used 
Table II

Solid Solubility of $\mathrm{Ti}, \mathrm{Cr}, \mathrm{Ni}$ and $\mathrm{Fe}$ in $\mathrm{Au}$ at Room Temperature and $900^{\circ} \mathrm{C}$, and Structure over Solid Solubility Estimated from Phase Diagram

\begin{tabular}{l|c|c|c}
\hline \multirow{2}{*}{ Element } & \multicolumn{2}{|c|}{$\begin{array}{c}\text { Solid solubility in } \mathrm{Au}, \\
\text { wt. \% }\end{array}$} & $\begin{array}{l}\text { Structure over } \\
\text { solid solubility }\end{array}$ \\
\cline { 2 - 4 } & Room temp. & $900^{\circ} \mathrm{C}$ & $\mathrm{Au}+\mathrm{TiAu}$ \\
$\mathrm{Ti}$ & $<0.45$ & $<2$ & $\mathrm{Au}+\mathrm{Cr}$ \\
$\mathrm{Cr}$ & $<6$ & $<14$ & $\mathrm{Au}+\mathrm{Ni}$ \\
$\mathrm{Ni}$ & $<2$ & 100 & $\mathrm{Au}+\mathrm{Fe}$ \\
$\mathrm{Fe}$ & $<3$ & $<26$ &
\end{tabular}

commercially as a white gold jewellery alloy, was tested.

The alloys were prepared as button-like ingots, of mass about $10 \mathrm{~g}$, by premixing their constituent metals and melting them in a tungsten arc furnace in an argon atmosphere. The ingots were hot rolled in stainless steel sheaths to sheets about $1 \mathrm{~mm}$ thick, and specimens for boronizing $(10 \mathrm{~mm} \times 5 \mathrm{~mm})$ were cut from the sheets and polished.

\section{Boronizing Treatments}

The test specimens were immersed in amorphous boron powder (96.6 per cent boron, 0.1 to $1.0 \mu \mathrm{m}$ diameter) in carbon crucibles (25 $\mathrm{mm}$ diameter). These were fed into an electrically heated furnace (Figure 2 ) under a shielding flow $(2 \ell / \mathrm{min})$ of argon gas. 'The temperatures of the specimens were recorded by a platinum/platinum-rhodium thermocouple inserted (Figure 2) in the bottom of the crucibles. The heat treatment cycles were as follows:

(a) For the gold-titanium, gold-chromium and gold-iron alloys: six hours at $950^{\circ} \mathrm{C}$.

(b) For the gold-nickel alloys, the melting temperatures of which are lowered at higher nickel contents: six hours at $900^{\circ} \mathrm{C}$.

(c) Treatments of some gold-chromium and gold-nickel alloys were also carried out at 800,850 and $900^{\circ} \mathrm{C}$.

After treatment each specimen was examined metallographically and by X-ray diffraction, and for hardness distribution with depth of the surface layer. Some specimens were also examined for distribution of elements by X-ray Microprobe Analysis.

Microhardness tests were made using a Vickers hardness machine under a $25 \mathrm{~g}$ load. X-ray diffraction analysis was carried out with 35 and $30 \mathrm{kV}$ accelerating voltage tubes with copper and cobalt targets respectively.

\section{Surface Hardening and Metallographic Results}

Surface hardening was found to occur with gold-chromium, gold-nickel and gold-iron alloys, but did not take place with goldtitanium alloys.
Table III

Chemical Compositions of Gold Alloys Used

\begin{tabular}{l|c|c|c|c}
\hline \multirow{2}{*}{$\begin{array}{l}\text { Nominal } \\
\text { alloy }\end{array}$} & \multicolumn{3}{|c}{$\begin{array}{c}\text { Chemical composition, } \\
\text { wt \% }\end{array}$} \\
\cline { 2 - 5 } $\mathrm{Au}-2 \mathrm{Ti}$ & $\mathrm{Ti}$ & $\mathrm{Cr}$ & $\mathrm{Ni}$ & $\mathrm{Fe}$ \\
$\mathrm{Au}-5 \mathrm{Ti}$ & 5.09 & & & \\
$\mathrm{Au}-1 \mathrm{Cr}$ & & 1.01 & & \\
$\mathrm{Au}-3 \mathrm{Cr}$ & & 2.97 & & \\
$\mathrm{Au}-5 \mathrm{Cr}$ & & 5.01 & & \\
$\mathrm{Au}-7 \mathrm{Cr}$ & & 6.48 & & \\
$\mathrm{Au}-10 \mathrm{Cr}$ & & 9.49 & & \\
$\mathrm{Au}-5 \mathrm{Ni}$ & & & 4.93 & \\
$\mathrm{Au}-10 \mathrm{Ni}$ & & & 10.29 & \\
$\mathrm{Au}-17 \mathrm{Ni}$ & & & 17.00 & \\
$\mathrm{Au}-35 \mathrm{Ni}$ & & & 35.60 & \\
$\mathrm{Au}-1 \mathrm{Fe}$ & & & & \\
$\mathrm{Au}-3 \mathrm{Fe}$ & & & & \\
$\mathrm{Au}-5 \mathrm{Fe}$ & & & & 3.12 \\
$\mathrm{Au}-10 \mathrm{Fe}$ & & & & \\
$\mathrm{Au}-20 \mathrm{Fe}$ & & & & \\
$\mathrm{Au}-30 \mathrm{Fe}$ & & & \\
"Commercial 18 carat white gold alloy & &
\end{tabular}

Fig. 2 Schematic illustration of boronizing process used

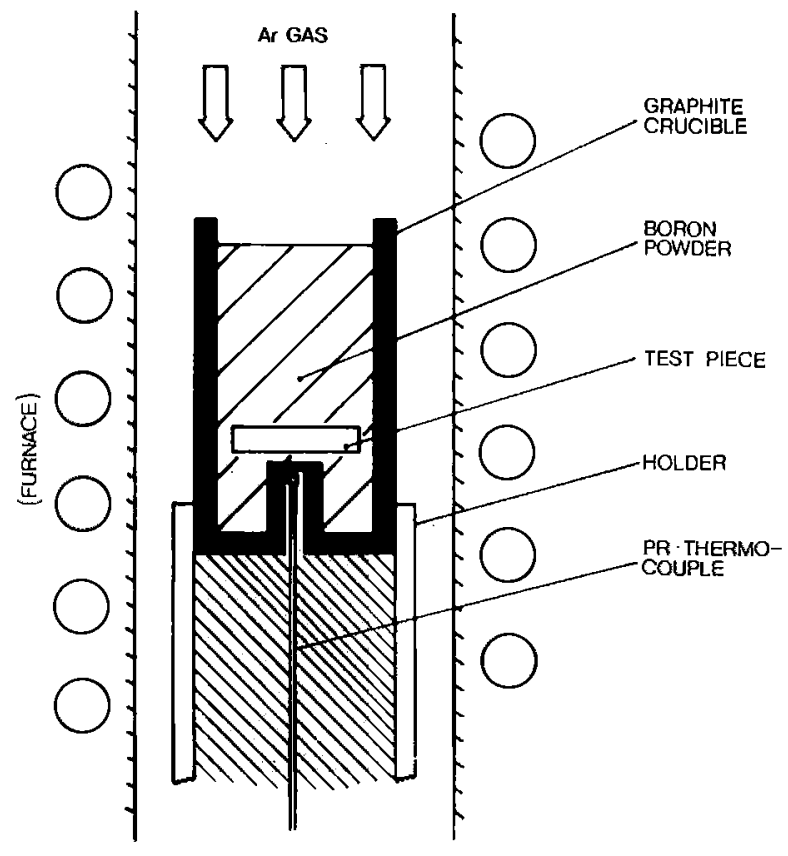




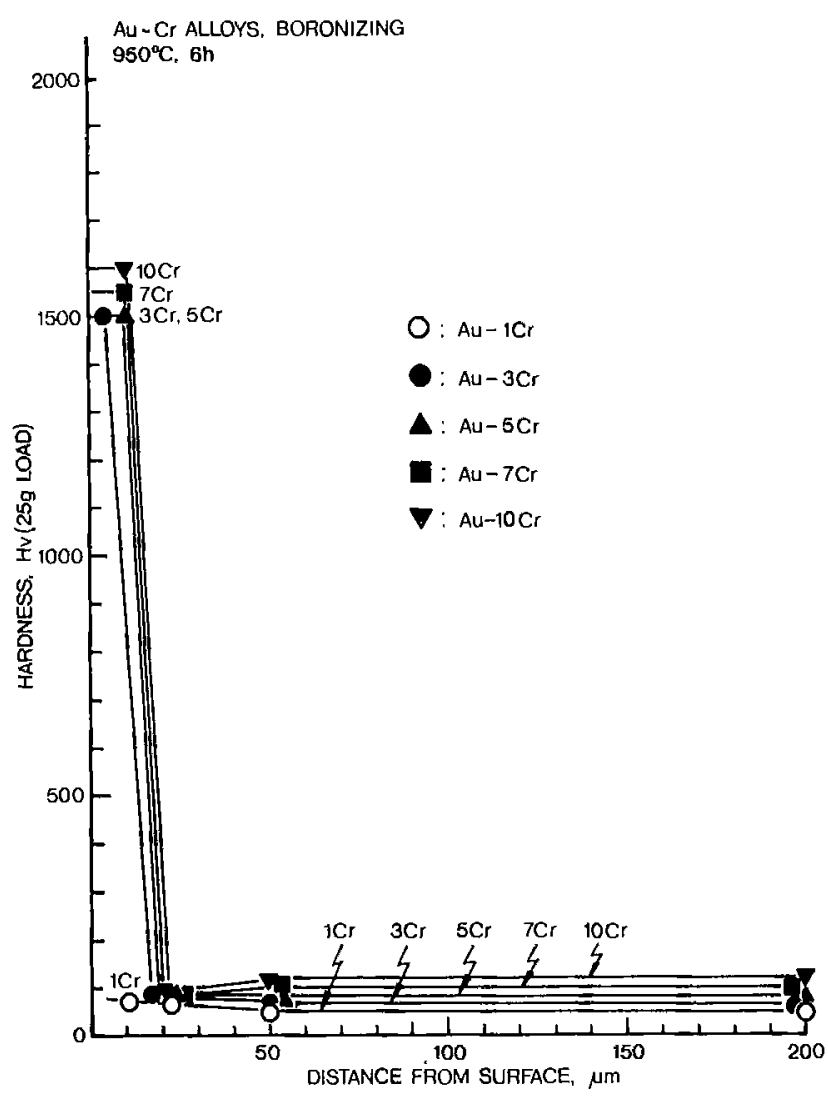

Fig. 3 Cross-sectional hardness distribution for gold-chromium alloys after boronizing treatment

\section{Gold-Chromium}

Figure 3 shows the variations in hardness with distance from the surface for the series of gold-chromium alloys which were treated by boronizing. Surface hardening did not take place in gold/1 chromium per cent alloy, but was pronounced in the alloys containing 3 per cent or more of chromium. The maximum hardness at the surface of the latter was in the range $\mathrm{Hv} 1500$ to 1600 irrespective of their chromium content and the thickness of the hardened zone ranged from about 10 to $20 \mu \mathrm{m}$. The untreated gold-chromium alloys did not show a corresponding increase in hardness with chromium content, measured up to 10 per cent.

Figure 4 shows the structure of the treated gold $/ 7$ chromium per cent alloy as revealed by scanning electron microscopy studies of a cross-section of a specimen. The hardened zone at the surface can beclearly seen as a flat layer, which has a jagged tooth-like interface between it and the underlying matrix. The thickness of this 'borided' layer did not increase with increase in the chromium content of the specimen.

Figure 5 gives the results of elemental analysis by Electron Probe Microanalysis of a cross-section of a gold $/ 3$ chromium per cent alloy

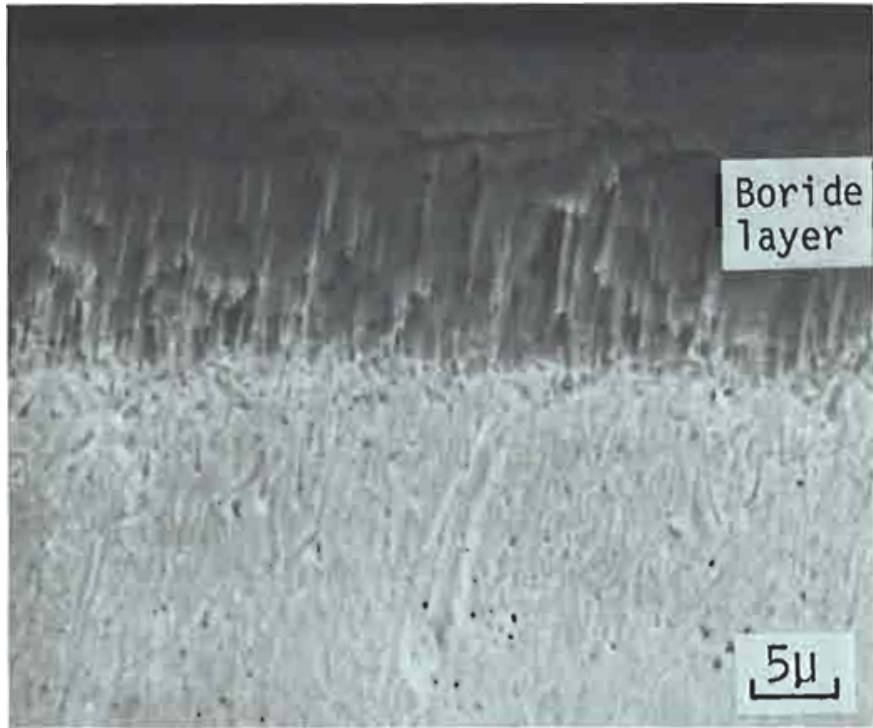

Fig. 4 Scanning electron microscopical photograph of the structure of gold/7 chromium per cent alloy after boronizing at $950^{\circ} \mathrm{C}$ for 6 hours, shown in cross-section

Fig. 5 Electron probe microanalysis results for the cross-section of gold/ 3 chromium per cent alloy boronized at $950^{\circ} \mathrm{C}$ for 6 hours
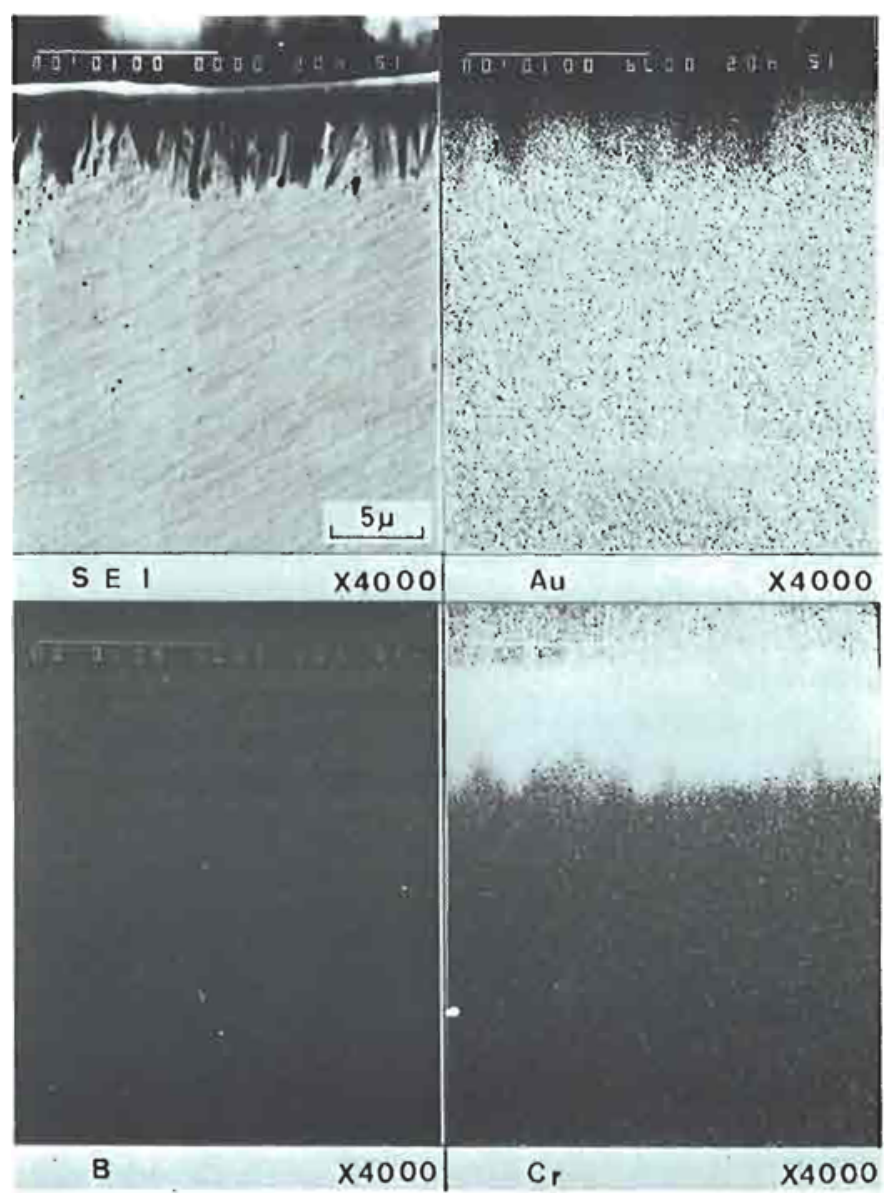


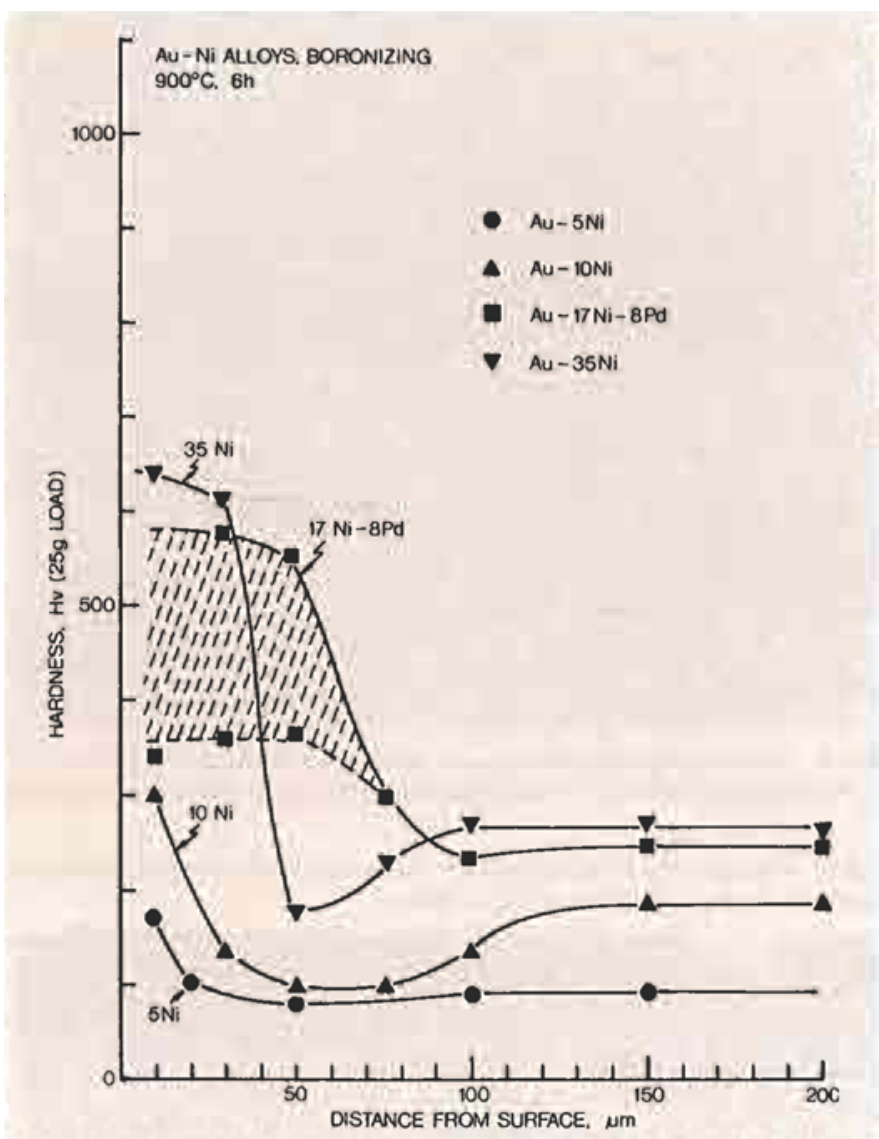

Fig. 6 Cross-sectional hardness distribution for gold-nickel alloys after boronizing

after treatment for six hours at $950^{\circ} \mathrm{C}$. Secondary emission is recorded in the upper left figure, while the other three figures show in clockwise rotation the distributions of gold, chromium and boron respectively. The hardened surface layer is revealed as containing less gold and significant amounts of boron and chromium.

\section{Gold-Nickel}

Surface hardening of this system became pronounced after treatment only in those alloys containing more than 10 per cent nickel (Figure 6). The maximum near-surface hardnesses observed were in the range of $\mathrm{Hv} 500$ to 700 , and in the gold $/ 35$ nickel percent alloy the thickness of the hardened zone reached about $50 \mu \mathrm{m}$. The gold/5 nickel percent alloy showed some surface hardening but the increase in hardness was small. The 18-carat gold/17 nickel/8 palladium per cent alloy showed appreciable surface hardening, but there was a considerable scatter in the hardness values near the surface which may be due to the presence in the surface hardened layer of a mixture of hardened and soft constituents.

In gold/10 nickel and gold/ 35 nickel per cent alloys the zones

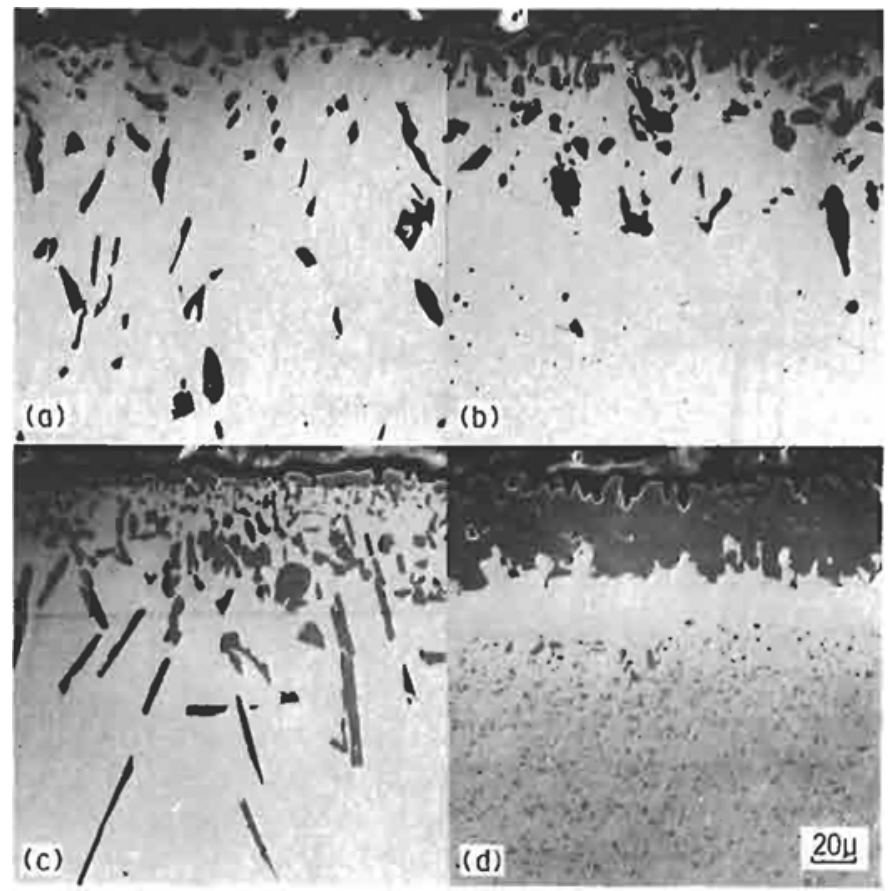

Fig.7 Structures in cross-section with SEM for gold-nickel alloys after boronizing at $900{ }^{\circ} \mathrm{C}$ for 6 hours; (a) gold $/ 5$ nickel, (b) gold $/ 10$ nickel, (c) gold $/ 17$ nickel $/ 8$ palladium, (d) gold $/ 35$ nickel per cent

immediately below the surface hardened layer tended to be softer, probably as a result of diffusion of nickel from it to the surface layer. This effect was not so evident in the 18-carat gold-nickel-palladium alloy.

The structures of the various nickel-containing alloys after treatment, as observed by scanning electron microscopy of crosssections, are recorded in Figure 7. With the binary alloys (Figures $7(\mathrm{a}), 7(\mathrm{~b})$ and $7(\mathrm{~d})$ ), the precipitation of boride can be seen to become more dense with increasing nickel content (from (a) to (d)). In the gold $/ 35$ nickel percent alloy (Figure 7 (d)), the precipitated material appears to have consolidated into a dense layer of boride, the thickness of which has decreased correspondingly. In the goldnickel-palladium alloy the precipitation of boride is less dense, but the zone in which precipitation can be seen is thicker than in the gold/10 nickel per cent alloy. The boride formation appears to occur preferentially along grain boundaries in the ternary alloy, and this is almost certainly the reason for the wide scatter in the hardness values of surface hardened layers of this alloy. The palladium probably promotes this grain boundary effect.

\section{Gold-Iron}

Surface hardening was observed in alloys of this type containing 10 per cent or more of iron (see Figure 8). The maximum hardness of the surface layer was in the range Hv900 to 1000 and the depths below the surface to which hardening extended were greater than those found with the gold-chromium and gold-nickel alloys, and 


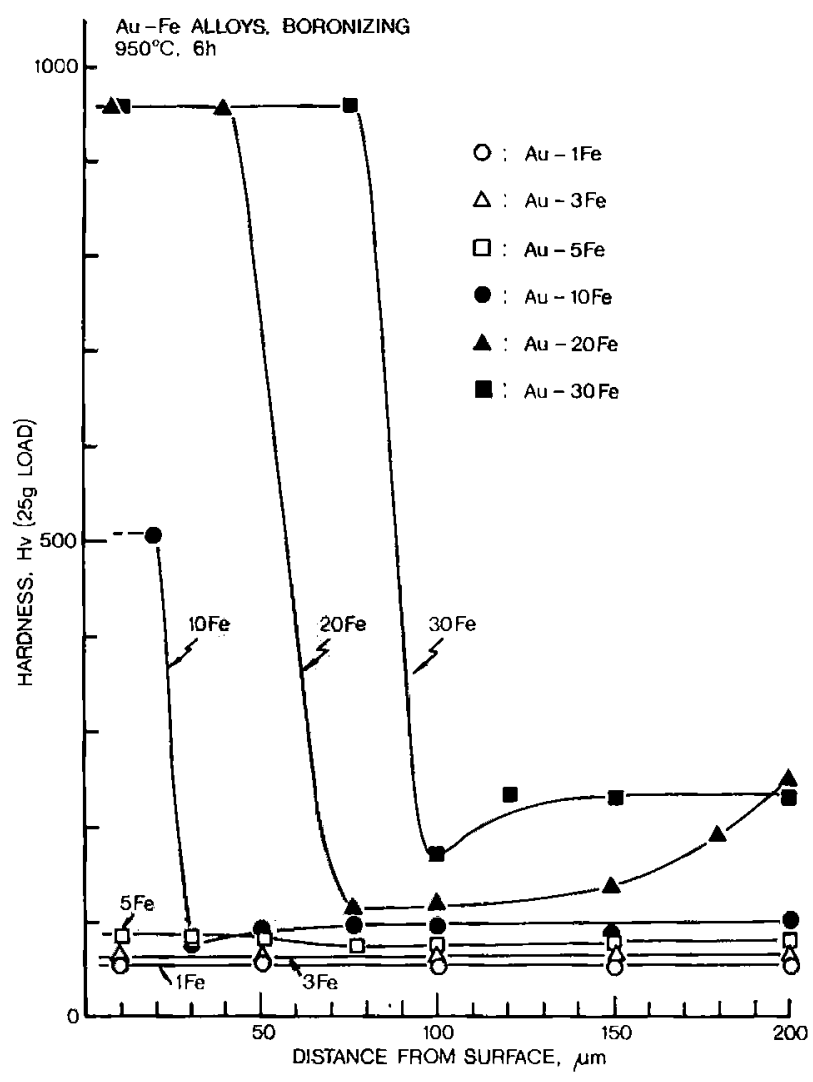

Fig. 8 Crass-sectional hardness distribution for gold-iron alloys after boronizing treatment

increased with the iron content of the alloys.

The structures of hardened surface layers of the gold $/ 5$ iton, gold/10 iron, gold/20 iron and gold/30 iron per cent alloys are recorded in the scanning electron micrographs shown in Figure 9. The hardened zones are dense and thick and are characterized by numerous boride spikes extending into the substrate matrix, and which are most pronounced in the case of the gold $/ 30$ iron percent alloy.

\section{Gold-Titanium}

No significant surface hardening was achieved by treatment of alloys containing up to 5 per cent titanium. As revealed by scanning electron microscopy (Figure 10), a very thin compound layer forms on treatment of these alloys, which has a thickness of $2 \mu \mathrm{m}$ or less.

\section{Boronizing Temperature}

Figure 11 shows the effect of variation in the temperature of the boronizing treatment on both surface hardness and depth of boride layer. It is seen that rise in boronizing temperature causes an increase

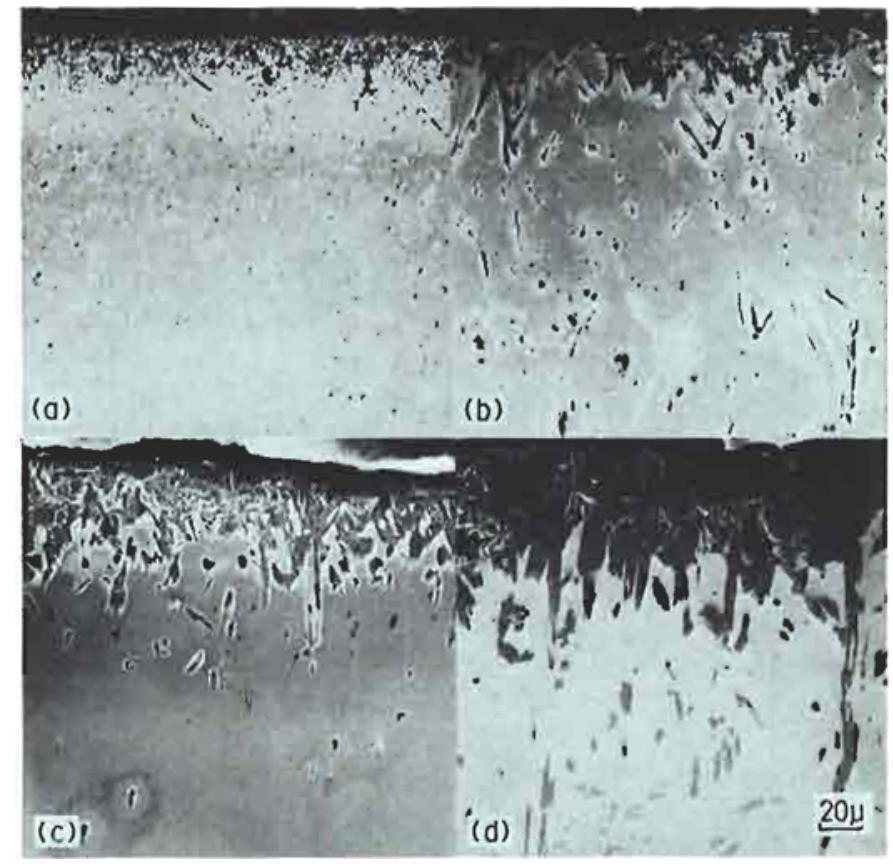

Fig.9 Scanning electron microscopical photographs of the cross-sectional structure of gold-iron alloys after boronizing at $950^{\circ} \mathrm{C}$ for 6 hours; (a) gold $/ 5$ iron, (b) gold $/ 10$ iron, (c) gold/20 iron. (d) gold $/ 30$ iron per cent

Fig. 10 Scanning electron microscopical photograph of the cross-sectional structures of gold $/ 5$ titanium per cent alloy after boronizing at $950^{\circ} \mathrm{C}$ for 6 hours

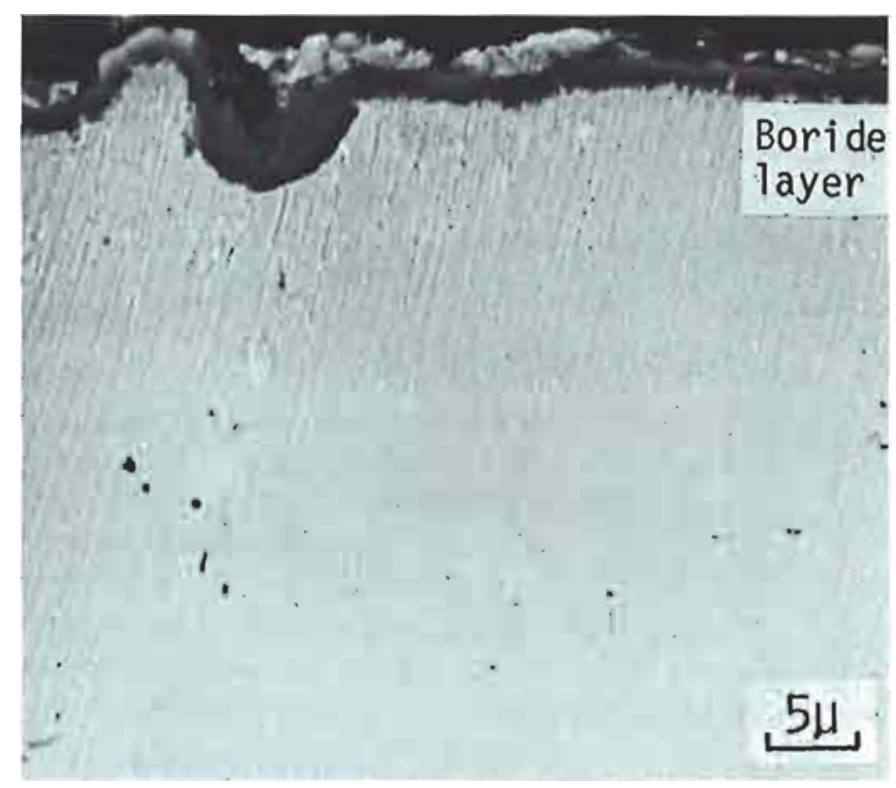

in both boride surface layer hardness and depth for both goldchromium and gold-nickel alloys tested. A particularly sharp increase in surfacc hardness of the gold $/ 7$ chromium per cent alloy was experienced when the boronizing temperature was raised from 900 to $950^{\circ} \mathrm{C}$. 


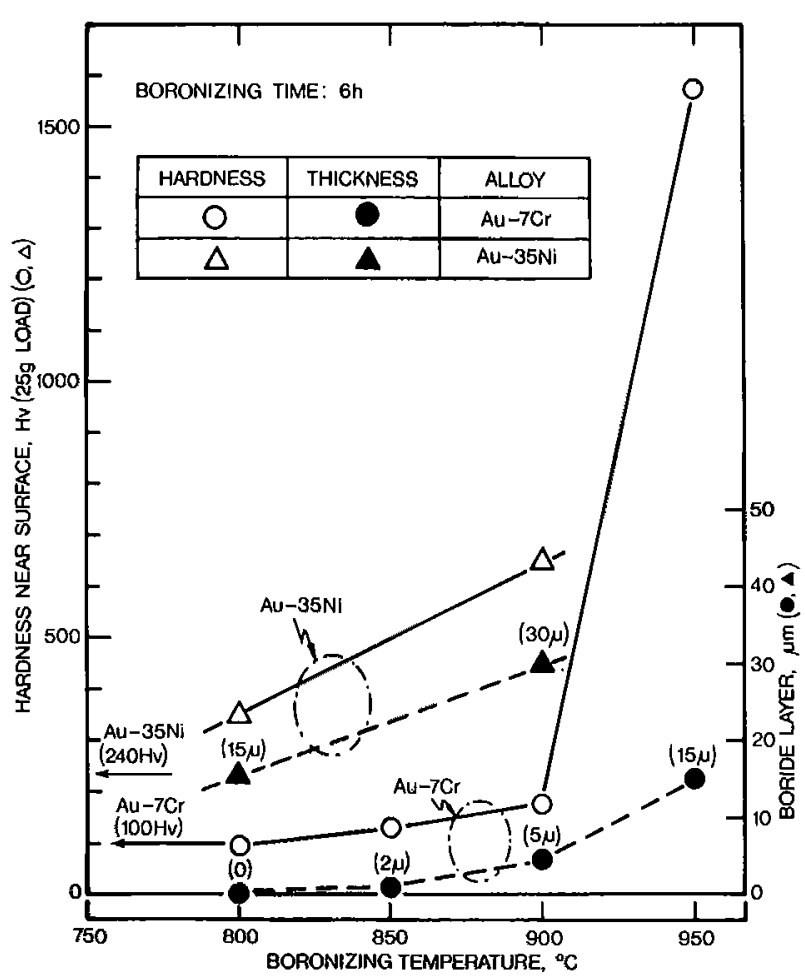

Fig. 11 Effect of boronizing temperature on the maximum near-surface hardness and thickness of the boride surface layer for gold/35 nickel and gold $/ 7$ chromium per cent alloys after the same holding time of 6 hours

Fig. 12 Effect of amount of alloying element on the maximuin nearsurface hardening for gold-titanium, gold-chromium, gold-nickel and goldiron alloys

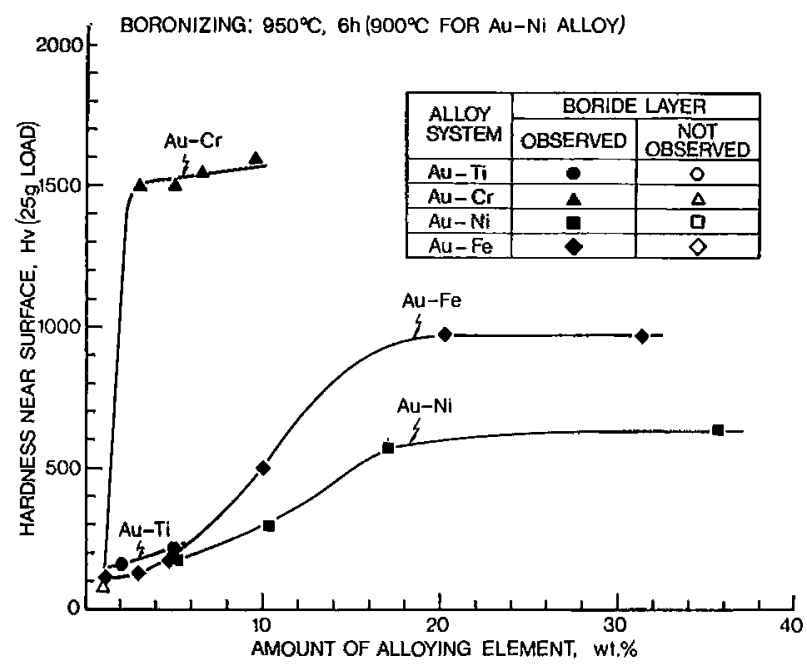

\section{Discussion}

The alloys of gold with chromium, nickel and iron have been shown to exhibit many common features in respect of their surface hardening by heat treatment in contact with boron powder(Figure 12). For each class of alloy there is a threshold value of the base metal content at which surface hardening becomes evident. In the case of gold-chromium alloys this threshold is between 1 and 3 per cent base metal content and for gold-iron and gold-nickel alloys it is between 5 and 10 per cent. Moreover, as the base metal contents of the alloys are increased above these threshold values, the hardnesses of the surface layers formed in boronizing increase to maximum values which are characteristic of each alloy system. Gold-titanium alloys do not, however, conform to this pattern.

\section{X-ray Diffraction Studies}

The phases which were detected in the boronized surface layers of the different alloys studied are set out in Table IV. The firstmentioned phase in each instance is that for which the X-ray diffraction patterns were most intense. The intensities of the patterns of the second and third-mentioned phases were less and in some instances very weak.

In the surface layer of treated gold-titanium alloys, the structures identified were those of $\mathrm{Au}(\alpha)$ and $\mathrm{TiB}_{2}$. The diffraction pattern of the latter was weak, in keeping with the thinness $(2 \mu \mathrm{m})$ of the layer as illustrated in Figure 10 .

In the case of the gold-chromium alloys the main surface phase identified was $\mathrm{CrB}$, although a secondary $\mathrm{CrB}_{2}$ phase was also observed together with $\mathrm{Au}(\alpha)$. The $\mathrm{CrB}_{2}$ phase was the dominant one in the alloy with the lowest chromium content ( 3 per cent).

In gold-nickel alloys $\mathrm{Au}(\alpha)$ and $\mathrm{Ni}_{2} \mathrm{~B}$ are the main phases detected from the range of alloys tested. Interestingly no definite pattern appears to be evident with respect to the existence of gold or nickel-based main phases throughout the range of gold-nickel alloys. $\mathrm{Au}(\boldsymbol{\alpha})$ with $\mathrm{Ni}_{2} \mathrm{~B}$ was detected from the boronized gold $/ 17$ nickel/ 8 palladium alloy.

In gold-iron alloys $\mathrm{FeB}$ was the main phase detected from the surfaces of gold/10, /20 and / 30 iron per cent alloys which were hardened on boronizing, and $A u(\alpha)$, with small amounts of $\mathrm{FeB}$, is detected in other alloys, low in iron, and for which boronizing had no hardening effect. The formation of $\mathrm{FeB}$ in gold is clearly seen in these unhardened alloys as of secondary intensity.

Additionally the authors have experimented in hard surfacing by the same process as above for other Au-X alloys (X-zirconium, hafnium, vanadium, niobium, tantalum, manganese and cobalt). The result showed that hard surfacing was possible with goldmanganese, -vanadium and -cobalt but was not detected with goldzirconium, -hafnium, -niobium and -tantalum.

Further work is to be carried out by the authors on other physical and chemical properties of the boride-hardened surface of these gold alloys before the technique can be considered suitable for industrial usage. 


\section{Conclusions}

Systematic attempts have been made to harden the surfaces of certain gold alloys by boronizing with the result that goldchromium, gold-nickel and gold-iron binary alloys have yielded boride surface layers of maximum hardnesses, thicknesses and compositions dependent on the alloys and treatment conditions. The minimum contents of alloying element required for the gold alloys to develop surface hardening were 3,10 and 10 per cent of chromium, nickel and iron respectively. The maximum hardnesses and thicknesses of the surface layers achieved were $\mathrm{Hv} 1500$ to $1600 / 10$ to $20 \mu \mathrm{m}, \mathrm{Hv} 500$ to $600 /$ up to $50 \mu \mathrm{m}$, and $\mathrm{Hv} 900$ to $1000 /$ up to $80 \mu \mathrm{m}$ for gold-chromium, -nickel and -iron respectively.

Gold-titanium failed to show measurable surface hardening after a boronizing treatment on alloys containing up to 5 per cent titanium due to the formation of a thin $(2 \mu \mathrm{m})$ layer of $\mathrm{TiB}_{2}$ which appeared to act as a barrier to further diffusion and growth in the conditions tested. It is possible that higher temperature and longer boronizing times will overcome this problem.

An 18-carat gold-nickel-palladium jewellery alloy also exhibited surface hardening, the extent of which showed a wide variation, probably due to boride formation occurring preferentially along grain boundaries.

Limited work on other binary gold alloys has shown that goldmanganese, -vanadium and -cobalt exhibited surface hardening on boronizing.
Table IV

\section{List of Phases Detected from Surfaces of Boronized} Specimens using X-ray Diffraction Analysis

\begin{tabular}{l|l}
\hline Alloy & $\begin{array}{l}\text { Phases detected from surface } \\
\text { of boronized specimen }\end{array}$ \\
\hline $\mathrm{Au}-2 \mathrm{Ti}$ & major, minor phases \\
$\mathrm{Au}-5 \mathrm{Ti}$ & $\mathrm{Au}(\alpha), \mathrm{TiB}_{2}$ \\
$\mathrm{Au}-3 \mathrm{Cr}$ & $\mathrm{Au}(\alpha), \mathrm{TiB}_{2}$ \\
$\mathrm{Au}-5 \mathrm{Cr}$ & $\mathrm{CrB}_{2^{\prime}} \mathrm{Au}(\alpha), \mathrm{CrB}$ \\
$\mathrm{Au}-7 \mathrm{Cr}$ & $\mathrm{CrB}, \mathrm{CrB}_{2^{\prime}} \mathrm{Au}(\alpha)$ \\
$\mathrm{Au}-10 \mathrm{Cr}$ & $\mathrm{CrB}, \mathrm{CrB} \mathrm{B}_{2}, \mathrm{Au}(\alpha)$ \\
$\mathrm{Au}-5 \mathrm{Ni}$ & $\mathrm{CrB}, \mathrm{Au}(\alpha), \mathrm{CrB} \mathrm{B}_{2}(?)$ \\
$\mathrm{Au}-10 \mathrm{Ni}$ & $\mathrm{Au}(\alpha), \mathrm{Ni}_{4} \mathrm{~B}_{3^{3}} \mathrm{Ni}_{2} \mathrm{~B}$ \\
$\mathrm{Au}-17 \mathrm{Ni}$ & $\mathrm{Ni} \mathrm{B}, \mathrm{Au}(\alpha), \mathrm{Ni} \mathrm{B}_{3}$ \\
$\mathrm{Au}-35 \mathrm{Ni}$ & $\mathrm{Au}(\alpha), \mathrm{Ni} \mathrm{B}_{2}, \mathrm{Ni}_{3} \mathrm{~B}(?)$ \\
$\mathrm{Au}-1 \mathrm{Fe}$ & $\mathrm{Ni} \mathrm{B}, \mathrm{Ni}{ }_{3} \mathrm{~B}, \mathrm{Au}(\alpha)$ \\
$\mathrm{Au}-3 \mathrm{Fe}$ & $\mathrm{Au}(\alpha), \mathrm{FeB}$ \\
$\mathrm{Au}-5 \mathrm{Fe}$ & $\mathrm{Au}(\alpha), \mathrm{FeB}$ \\
$\mathrm{Au}-10 \mathrm{Fe}$ & $\mathrm{Au}(\alpha), \mathrm{FeB}, \mathrm{Fe} e_{2} \mathrm{~B}(?)$ \\
$\mathrm{Au}-20 \mathrm{Fe}$ & $\mathrm{FeB}, \mathrm{Au}(\alpha), \mathrm{Fe}{ }_{2} \mathrm{~B}(?)$ \\
$\mathrm{Au}-30 \mathrm{Fe}$ & $\mathrm{FeB}, \mathrm{Fe} \mathrm{B}_{2} \mathrm{Au}(\alpha)(?)$ \\
& $\mathrm{FeB}, \mathrm{Fe} \mathrm{B}_{2} \mathrm{~B}, \mathrm{Au}(\alpha)(?)$
\end{tabular}

\section{Acknowledgement}

The authors wish to thank Mr. Kenji Tohmoto for his help and assistance in the experimental work.

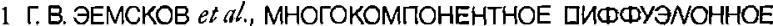
НАСЫШЕНИЕ МЕТАПЛОВ И СПЛАВОВ, 1978

2 E.T. Turkdogan, 'Physical Chemistry of High Temperature 'Technology', Academic Press, New York, 1980

\section{References}

3 S. Ohmori et ah, J. High Temp, Soc, 1982, 8, (6), 221-229

4 M. Hansen, 'Constitution of Binary Alloys', McGraw Hill, New York, 1958

5 R.P. Elliott, 'Constitution of Binary Alloys, First Supplement', McGraw Hill, New York, 1965

\section{Fabrication of Patterns Smaller Than 0.2 Micrometres}

It has been recently reported (Electronics, 1984, February 9th, 71) that a prototype ion-beam system for fabricating patterns smaller than 0.2 micrometres has been developed by the Mitsubishi Electric Corporation research and development laboratory. The system is capable of deflecting a gallium ion beam of diameter smaller than 0.1 micrometre over an area of $200 \times 200$ micrometres. Larger patterns can be stitched together by moving the work stage. Researchers in the laboratory have used the beam in a lift-off process to fabricate an aluminium gate 0.2 micrometres long.
A thin gold film overlay on a thick tesist layer is milled by the beam, and the residual gold acts as a mask in the removal of the unprotected resist by reactive ion etching.

It is estimated that practical application of ion-beam fabrication in this way - probably for 4 megabyte dynamic random-access memories - is still about three years away. Mitsubishi is expected to expand the range of ion sources at its disposal so that the system can be used for unmasked ion implantation and in the deposition of thin films. 